\title{
Main Approaches and Concepts Management Today and in the Future
}

\author{
Gabdelakhat R. Latfullin*, Valentina G. Smirnova, Olga N. Gromova, Nina V. \\ Bobyleva
}

Department of management theory and organization, Institute of industry management, State University of Management, Moscow, Russia

${ }^{*}$ Corresponding author. Email: gr_latfullin@guu.ru

\begin{abstract}
The purpose of the results of this research is to consider the modern methodological foundations of the theory and practice of managing socio-economic systems. Modern concrete approaches and management concepts are considered. The hypothesis of their research is based on the laws of Economics and management and on the classical methodological basis: system, complex, situational, etc. An important place is given to retrospective, anthropological, and creative approaches in the context of digitalization of the economy and management. A special place in research is given to knowledge management. We also study the positive and negative impact of artificial intelligence on the human factor in the modern ecosystem. The validity of the considered methodological approaches is proved by the use of publications of leading scientists, materials of international conferences, discussions, etc.

The anthropological approach in the conditions of intensive development of artificial intelligence is very important and relevant. Anthropology is a humanitarian approach to the methodology of the XXI century, the use of which, thanks to a unique combination of fundamentals and a set of appropriate techniques, allows you to solve a variety of problems: from the knowledge of the worlds of the past and present to increase the level of sales in the high-tech sector.
\end{abstract}

Keywords: management, methodology, retrospective, anthropology, approaches, concepts, knowledge, creativity

\section{INTRODUCTION}

Time is inexorably fleeting. We have entered the third decade of the XX1 century. We live in a complex, rapidly changing world. At the same time, we are aware of our historical memory as the genetic code and the criterion for the viability of each organization and each of Us! For at least two hundred years, the paradigm has been known that the root cause, the basis of prosperity or decline in socio-economic systems, is good or bad governance, its methodology and subject matter.

In scientific and practical terms, the search for a model of ideal organization management went on throughout the $\mathrm{XX}$ century. Patriarchs of American management $\mathrm{T}$. Peters and R. Waterman in the work "in search of effective management", having studied 43 of the best, superbly managed American companies, identified the principles of management that determine their success: commitment to action; proximity to the consumer; autonomy and enterprise; human productivity; connection with life; loyalty to their business; a simple form, a small management staff; unity of freedom and discipline [1]. Close to these principles were identified by another wellknown American theorist, D. S. sink [2]. Management guru Tom Peters believes that modern management is implemented in a completely different organizational reality than in the twentieth century. In the words of the management classic P. Drucker, management, both in the public consciousness and in the scientific world, is identified exclusively with "business management" [3].

The basics of the" new model "of management are discussed in the works of the Creator of the" $\mathrm{Z}$ " theory, William Ouchi, who, identifying the specifics of management methods in the best Japanese companies, came to the conclusion that the best Japanese and American companies are managed in the same way. However, within each country, there are significant differences between leading and lagging companies [4]. The object of this research is socio-economic systems, and the subject is human relations about management, while highlighting the human being as the highest value. The prospects of this research are very relevant, because we are all connected with management. Indeed, it can be 
argued that there are no bad States, organizations, and companies, but there is bad management in them. We live in a complex, rapidly changing world. in a world where processes have become much more complex, and the speed of decision-making has increased to a cosmic level. The modern world is no longer waiting for those who are focused on yesterday - today it is ruled by those who know how to anticipate tomorrow and change it according to their needs. The changes in the world that are taking place today could not affect such a specific sphere of human activity as management, its subject, and methodology.

The methodology of this research is based on both classical methods and methodologies, and on the actual realities of the development of the theory and practice of managing socio-economic systems, while highlighting crisis and turbulent situations.

Noting the main results of this research, it is necessary to highlight the relevance and prospects of such approaches as retrospective, which is often confused with the historical approach. The retrospective approach in terms of its practical application involves the use of historical knowledge, if it is, of course, available or not falsified to calm the public consciousness.

The management category, like any other category, has many definitions. We adhere to the most well-established definition that it is, first of all," impact", although we can say more mildly - "communication" Indeed, impact is the interaction of the subject and the object of management.

The little-studied impact of an object on the subject of management is important and relevant today. It is believed that the higher the management hierarchy, the more competent, talented, and wise managers manage it. Even if this is so, because wisdom also needs to be managed, meaning-the impact from the lower levels of the hierarchy to the upper levels. The object of management has its own intelligence, managerial potential and behavior, which means that it is not always inclined to turn in the direction where it is pushed and attracted by the "mechanisms of the subject of management". Of course, the impact of the subject is more formalized than the impact of the object on the subject, which is more informal. Hence, the problem of interaction between the subject and the object of management, in which the leading role belongs to the subject of management, is actualized. Any impact is characterized by a contribution, i.e. an increase in the impact or a counteraction that weakens this impact. Here, it is important to move from the categories of governance under consideration to the actual implementation of them by specific people, i.e., to mechanisms and methods of democratization and self-government.

Time requires a clear understanding of the scale and essence of the ongoing rapid changes in all areas of the economy and management, as well as trends, new conceptual approaches (digitalization, anthropologization, etc.), new paradigms for the successful implementation of the National Project on the main directions of the country's strategic development until 2024 [5]. And it depends on whether the solutions to these problems will be based on scientific recommendations, to what extent these recommendations developed by science will be reliable and correspond to the best achievements of world experience, on the one hand, and the peculiarities of the internal Russian environment, national traditions and mentality, on the other, and how well trained management personnel will be. Finally, whether management science will become a priority in the country. The above information updates our research [6-9].

Theories of management and self-government, as a full and objective basis of the science of management, have a common and own methodology. Methodology is a system of principles of scientific research. The methodology of management science is a set of research methods, procedures, and techniques used in the knowledge of management processes [10].

Both in everyday speech and in scientific literature, the word "approach"is often used. As a scientific term, it occurs in phrases with the words: system, complex, aspect, scientific, differentiated, individual, probabilistic, situational, etc. In General, an "approach" is a methodological setting (analyst, designer, Manager, politician, organizer, etc.) for a certain order and/or method of action in accordance with the original, accepted or normative model (representation, judgment, classification, perception of the situation, understanding the essence of the task, etc.).

Over the past 20-30 years, the attitude of management to human resources has changed radically, although in the 20 s of the last century, the American researcher and management practitioner Henry Gantt believed that "the problem of the human factor is one of the most important problems of management" [11].

Advanced organizations have mastered a huge Arsenal of tools and methods of working with staff, "balancing" between the technocratic (technocentric) and humanistic (anthropocentric) approaches. Despite the huge potential, hopes, and appeal of a technocratic approach based on robotics, computerization, the creation of automatic factories, and in General, over time, the displacement of the main labor force from production, the trend of this approach has not justified itself. The consequence of this was a consistent shift of emphasis on the holistic approach, which is based on long-term development of intellectual and labour potential of the worker, in which man is seen not so much as a basic resource, and as the Supreme value, that certainly contributes to the development of entrepreneurial management, on the basis of democratic management and self-development.

\section{METHODOLOGY}

When considering modern approaches to management science, it should be taken into account that the rejection of classical schools and established concepts of the past would not lead to a loss of manageability today, seeing 
only trends and approaches and remembering that everything new is forgotten old. After all, many of the discussed trends in the development of management science are often just myths about management.

The present scientific research of the State University of management, analysis of domestic and foreign sources on management problems, allow us to outline the main conceptual approaches, management paradigms of the XXI century. There is no doubt that all these trends and concepts are interrelated and mutually dependent. Let's consider such campaigns, which in our opinion are the most relevant today and in the future:

1) The concept of entrepreneurial management is formed as one of the emerging trends in the management of organizations in the coming century, one of the new approaches being developed. From the point of view of the entrepreneur, such management is more selfgovernment.

2) The humanitarian approach based on the implementation of managerial anthropology is a humanitarian approach, a methodology of the XXI century, the use of which, thanks to a unique combination of fundamentals and a set of appropriate techniques, allows you to solve a variety of tasks: from understanding the worlds of the past and present to increasing the level of sales in the high-tech sector.

3) Knowledge management), as a new concept of management science was formed in the mid-80-90 years of the last century, when intangible assets, organizational knowledge, and intellectual capital began to provide the company with strategic competitive advantages [12]. Japanese researchers I. Nonaka and H. Takeuchi, assessing the role of knowledge, figuratively noted that the realization that knowledge is a new resource of competition, struck the West like a lightning flash [13].

4) A retrospective approach that pays attention to a General methodological approach that provides for the study of the main historical stages and periods of development of management theory: evolutionary, revolutionary, with the aim of competent orientation in trends, concepts, organizational schools, paradigms and perspectives of management. The retrospective approach is wrongly identified with the syndrome of conservative thinking as a commitment to established, although morally obsolete, forms of social existence. It is a method of action that takes into account the information already acquired by mankind, the knowledge of laws that can be systematized and formulated in the form of legal norms and rules that organize the behavior of individuals and groups - regulating the life of society.

If our life is a way of storing information (genetic), then the presence of historical memory in the people, in the organization, in You and me, is the criterion for the viability of the social organism.

We can also say that when we look in the mirror of history, we also see ourselves. If only the mirror wasn't crooked. Knowledge of the past is the cultural memory of the people, which helps them to foresee and understand the present and future.

The mainstream of uncertainty in management. For more than 20 years, the Department of management theory at the State University of management has been developing theory and practice under the guidance of A.V. Rostovskaya of the concept "managing the unexpected: the stage space of the game as a resource for the professionalization of a Manager".

Let us look at the selected concepts and approaches in more detail in the discussion section.

\section{DISCUSSION}

1. The concept of entrepreneurial management.

This century is also called the century of entrepreneurs, i.e. the century of entrepreneurs.

The term "entrepreneurship" was coined by Richard Cantillon in the 17th century, although it has been used by economists and anthropologists before. The concept of entrepreneurial management is formed as one of the emerging trends in the management of organizations in the coming century, one of the new approaches being developed. From the point of view of the entrepreneur, such management is more self-government. Entrepreneurship has come to be seen as a way of thinking, a style of behavior, a way of life.

In fact, the entrepreneur is relatively subordinate to no one, there are no superiors over him, he manages his business and other people involved in it at his own "risk". Naturally, it is accountable to special bodies of the state and civil society that exercise supervision and control. This can explain the tendency of many people, including a large army of managers, to strive for entrepreneurship. This tendency forces managers of large organizations to allow bootlegging, i.e., to use the Internet. allow managers to use part of their working time to pursue their business interests. Here, there is a clear trend that management to some extent acquires the features of entrepreneurship, i.e. the new economy gives birth to "new" management.

Naturally, when any organization enters a new situation, the managerial activity of its teams sharply increases. Therefore, it is relevant to study the conditions of the organization's life in which labor collectives should become active subjects, and not just objects. This situation necessarily strengthens approaches to General anthropology in the system of management and selfgovernment.

Despite numerous studies of the category of selfgovernment, today there are almost unsolved fundamental, theoretical and methodological issues, at the same time, the need for urgent practical solutions to emerging problems forces us to look for solutions without waiting for scientific recommendations. And although practice significantly enriches the scientific understanding of selfgovernment, the development of the latter is not only hindered, but more often misdirected by the old party 
paradigm, which is based on methodological and theoretical provisions, almost without taking into account the provisions of General anthropology.

Self-government for the Russian economy should be considered as a qualitatively new phenomenon that has retained essentially only the old name in the new conditions - the conditions of denationalization of property and privatization of enterprises, the rapid development of its private forms, as a relevant part of measures for the transition to market relations.

Hence, self-government on the example of the labor collective is not just the participation of personnel, workers in the management of production. And this is not only the kind of governance that best represents the interests of the majority, although the degree of majority participation can certainly be seen as a criterion for democratic governance. But, in our opinion, it is a mistake to equate self-government and democratization, although they can "step in step". Often this is done until the complete combination of these concepts, i.e. until they are indistinguishable, regardless of the order of movement. There may be cases when there is self - government but there is no democracy, or Vice versa, there are signs of democracy but there is no self-government.

Any complex system presupposes, by virtue of its hierarchical structure, the presence of self-government: its subsystems experience (on themselves) not only external controlling influences, but also, to the extent of their independence (autonomy) or independence from the center, develop certain measures themselves - internal influences. In other words, management is an external influence that enters the system in a ready-made form from outside, and self - government is an internal influence that is generated by the system itself, which is formed inside. This means that the opposite of democracy is not centralization, which causes external influences, which was usually allowed when considering and interpreting the forms of implementation of the so-called principle of democratic centralism, but autocracy. It is obvious that in the conditions of strict centralization, management can differ in the degree of democracy, if only because the parameters of its formal organization can be overlaid with individualized features of the management style. The opposite of centralization, therefore, is not democracy, but decentralization. When comparing the concepts under consideration, which may be essential for the purposes of analysis and / or design of management systems, the dialectic of elements of professional and social, formal and informal in the management of the organization should be taken into account.

2. A humanitarian approach based on the implementation of managerial anthropology

It is difficult to imagine the development of management science without setting and using the fundamental realities of managerial anthropology. Each of us can consider himself an anthropologist because each of us is someone, something, and, above all, himself, always manages. Indeed, each of us is always connected with social organization throughout our life, beginning with the development of an infant in the womb, going from stage to stage of childhood, adolescence, youth, adulthood, old age and death.

Western companies are increasingly turning to anthropologists in their work, who, on the instructions of the employer, conduct rather unusual research, sometimes provoking protests from marketers. For example, in the United States in recent decades, more and more anthropologists have become involved in such technology giants as: Apple, Intel, Mikrosoft, Xerox, etc. They positively assess the effectiveness of the work of anthropologists, their specific contribution to the final results of the Corporation. The U.S. government employs an ever-expanding number of anthropologists in its field of expertise. A comprehensive analysis clearly shows that if companies or government agencies do not understand the peculiarities of the culture of different peoples, they are increasingly losing out in a tough competition. For example, in order to explain to American soldiers fighting in Iraq and Afghanistan the peculiarities of local cultures and the mentality of the multinational population, the American government hired anthropologists of various fields to conduct specific research.

Indeed, management science studies people's attitudes about management, Economics studies economic relations, and organizational science studies people's organizational relationships. But every person or group in an organization is unique. This uniqueness is manifested in the characterological features of each individual and in their interaction. Does management science take these features into account? You can answer Yes or no. The anthropology of management answers these and related questions.

Anthropology - (from the Greek words anthropos - man, and logos - concept, doctrine, mind) is a field of scientific knowledge that studies the problems of human origin, existence in the natural and artificial environment, i.e. it is the science of man in the broadest concept. It is known that a person is studied by more than two hundred Sciences, and each of them finds its own subject in it. It can be argued that each human science has its own anthropology, i.e. the process of anthropologization of the human Humanities is underway (Fig. 1).

The concept of "anthropology" was first used by Aristotle, who designated the field of knowledge, the object of study of which is the spiritual side of human nature. This term has existed in this sense for more than 1000 years. But this is a subject of historical anthropology. 


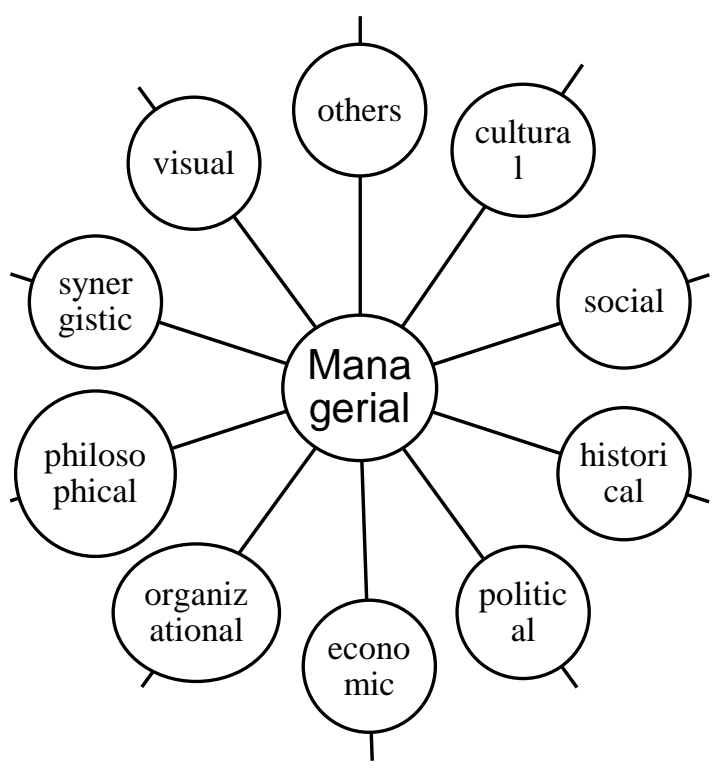

Figure 1 The main types of anthropology implementation

It is also obvious that managerial anthropology (spiritual) and physical anthropology (bodily) are inseparable from each other, just like the soul and the body.

Moreover, if we interpret anthropology as the unity of soul and body, then digitalization can be considered figuratively as the unity of man and digital technology. Indeed, the technical and technological problems created by the requirements of unconditional provision of permanent collection, independence of processing and responsibility for presenting information are significantly increasing. "They emphasize the need to ensure absolute protection of digital control parameters and procedures from subjective distortion, regardless of its purpose. It is obvious that without solving these problems at the methodological level, the subject of management is inevitably doomed to constantly recurring "failures" in the implementation of specific procedures for the implementation of digital management. In overcoming these problems, technological solutions are determined by the need to develop and maintain open, unified digital management software.

Certainty and timeliness in the development of options for management decisions, calculation of

indicators and the choice of the adopted impacts the need for operational support for their

the adequacy of measuring results and accounting for them in the process of further functioning efficiently complicate the role and significantly extend the capabilities of digital technologies at all stages of interactions of subjects and objects of management [10].

3. Knowledge management

Now, the main source of economic and social development and their management around the world are intellectual resources, which are based on knowledge. Knowledge management (knowledge management)) as a new concept of management science was formed in the mid-80-90 years of the last century, when intangible assets, organizational knowledge, and intellectual capital began to provide the company with strategic competitive advantages.

It is no accident that scientists say that knowledge is a new battleground for every subject of government. For many centuries, and research in this area has been devoted to many works. Knowledge was considered from philosophical, historical, psychological and other positions. The famous English scientist, philosopher and political figure Francis bacon wrote back in 1597: "Knowledge is power. We can do as much as we know" [14].

According to experts, the category - "knowledge management" - is $70 \%$ of the human factor, $20 \%$ of the process and $10 \%$ of the technology. People as creators and carriers of implicit knowledge are a key element of the knowledge management system, and intellectual activity becomes the main factor of competitiveness and efficiency of the business organization.

In a new or innovative economy, the object of management is intellectual resources, so an important task of management is their transformation into the intellectual capital of the organization in order to increase the competitiveness and efficiency of its activities. The basis of an organization's intellectual resources is the knowledge and competence of its employees, so the management of intellectual resources is based on knowledge management.

According to the American scientist David tis, the essence of a firm in the new economy is its ability to create, transfer, aggregate, integrate and exploit the asset of "knowledge" [15].

Despite the importance of information technology, it should be borne in mind that the main carriers and users of knowledge in the company are people and the anthropologization of management takes on a special role. Indeed, knowledge is a product of people's creativity. Creativity manifests itself in the context of intensive intellectual communication in the form of discussions, conferences, meetings, seminars, and other available ways of sharing knowledge.

The basic values of a knowledge culture are: generating ideas, creativity, innovation, information openness, readiness for change, and learning. Corporate culture should promote the creation of new knowledge, generation of ideas, innovation, creativity in all divisions of the company. Employees working in a business organization, using their knowledge, must learn to generate new ideas, as well as strengthen the innovative element in ideas that were born elsewhere. The main problem is what conditions people need to create and how to motivate them so that the process of generating ideas becomes permanent.

Since the 80 's of the last century, with the emergence of new management concepts, the role of organizational culture is constantly increasing. Organizational culture has 
become one of the key characteristics that affect the effectiveness of company management. There has never been a greater need to study organizational culture as an object of change, introduction of new approaches and management concepts.

As one of the important trends in management, we should highlight the increasing role of creativity in business, due to the fact that the main factor of competition is innovative products and services, the creation of which requires new creative ideas. This explains the increased interest of managers in the creative abilities of employees and their development opportunities, the peculiarities of talent management, and the organization of creative processes in the company.

An important role in creativity is played by the power of imagination, which is expressed in the ability of the human mind, based on accumulated experience, knowledge and observations, to mentally create situations, actions, behavior, characters, etc. People as creative individuals are distinguished by originality of views and approaches, openness, curiosity, perseverance, receptivity to new ideas, the ability to concentrate on the essence of problems, and most importantly - imagination. We should cite the statement of the brilliant scientist albert Einstein: "Imagination is more important than knowledge. Knowledge is limited. Imagination is boundless." Bill gates, the founder of Microsoft, believed that"our only productive asset is imagination." Realizing the importance and necessity of creativity, Steve jobs, one of the founders of Apple, placed a magnificent white Grand piano and a BMW car in the Central foyer of the headquarters with the banner "I believe that people come up with great ideas when they see great creations."

Companies are interested in hiring creative people with creative abilities. New special positions of managers are being introduced, whose task is to develop creativity and generate new ideas necessary for creating innovative products. A striking example is the appointment in January 2011 to the position of top Manager-Director of creative innovations of the largest manufacturer of computer processors, Intel, of a creative personality-a singer and producer of the group "Black Eyed Peas" WILL. I. AM, seven-time Grammy award winner.

Scientists develop approaches, principles and methods that allow developing the creative abilities of people and organizations as a whole, and consider certain aspects of this problem. However, despite the ongoing research, a holistic view of management as creativity has not yet been formed.

Based on the results of the research, the monograph " management of creative activity. How to organize the creative process in the company" [16]. Features of such modern concepts as knowledge management, creative management, organization creativity management, talent management, design management are revealed. These concepts allow to get a complete picture of the existing concepts of creativity management and the possibility of their use in organization management.
Attention is paid not only to theoretical approaches, but also to the analysis of practical experience, that is, specific forms, methods, and management methods used by foreign and Russian companies, and recommendations are given to managers that can be used in practice to create the necessary organizational environment for creative activity.

4. A retrospective approach

The retrospective approach is a method of studying modern social life, which allows us to adequately perceive its Genesis, "highlight" the background of current problems

It is a mistake to identify the retrospective approach with the syndrome of conservative thinking as a commitment to established, even morally obsolete, forms of social existence. It is a method of action that takes into account the information already acquired by mankind, knowledge of laws that can be systematized and formulated in the form of legal norms and rules that organize the behavior of individuals and groups - regulating the life of society, and can be statistical data recorded by contemporaries eyewitnesses of events, individual facts, historical Parallels and paradigms. In other words, a retrospective approach takes place when precedents are taken into account when solving modern problems.

The retrospective approach from the point of view of its practical application involves the use of historical knowledge, if, of course, it is available or not falsified to calm the public consciousness. The benefits of acquiring such knowledge or studying history can be seen in the following:

- Knowledge is interesting in itself, and historical knowledge is no exception, and new knowledge enriches both the individual and society, and historical knowledge not only develops erudition and intelligence, but can also have quite pragmatic value.

- Historical justice is restored in relation to the names of forgotten figures of the past as authors of new ideas, scientific provisions and/or practical innovations for that time.

- The knowledge that even our remote ancestors - the inhabitants of the previous centuries-possessed, in many respects, retains its applied, methodical content, meaning to this day.

- A number of ideas, comments, suggestions made earlier were not perceived and not noticed by contemporaries, and, moreover, were not known to descendants, which led to the repetition of sad consequences in the economic, economic, and, therefore, political situation of the country.

- Knowledge of the past is the cultural memory of the people, which helps them understand the present. Ignorance of the past not only harms knowledge of the present, but also jeopardizes any attempt to act in the present and foresee the future.

- Historical paradigms have many Parallels with the problems of the present. it is not for nothing that the so- 
called empirical school of management has emerged in scientific management.

- Elements of the present, even in an undeveloped, primitive and/or implicit, embryonic form, it turns out, once already took place in reality.

We all need to learn how to" not fall twice on the same rake", to learn lessons from history. Adjusted for conditions and time scales, the retrospective approach can be very useful and instructive.

The deeper you dig in time, the more historical Parallels you can see.

What prevents the retrospective approach, which has so many applications as shown above, from being applied more widely and having a greater impact on practice? There are, as we believe, a number of reasons for this:

- insufficient dissemination of historical knowledge due to the shortcomings of modern higher education systems;

- insufficiently high quality of historical information presented in mass communications, lack of "historical truth" and silencing of certain facts in a number of published works on a historical theme, clogging of historical works with ideological layers of party propaganda intended for "forming a new person":

- the relative lack of development of the historical science itself, which focuses more on the tandem of "events and chronologies" than on the identification of General laws of the historical process;

- falsification of certain historical events in the interests of the ruling elites or the quasi-scientific lobby;

- underestimation of historical knowledge in the mass consciousness, when the study of other scientific disciplines is considered more important from a utilitarian and pragmatic position.

Removing these reasons will facilitate the effective use of the possibilities of a retrospective approach. It is necessary to understand that without historical knowledge, there is no completeness of information, and without it, organization and a state of social order are unattainable, as well as the historically verified choice of a strategic course of development of society is impossible.

Thus, undeservedly forgotten retrospective experience is important not only in the science of management, but also in any science.

5. The mainstream of uncertainty in management

Any Manager increasingly has to make management decisions in an environment of uncertainty and lack of information. In the conditions of turbulence, abrupt changes in the external environment, respectively, and internal, the mainstream of the organization's development changes dramatically. Who could have predicted the systemic turbulence of the coronavirus? The method of the stage platform as a resource for the professionalization of managers sets the model of organizational and managerial activity. It is not enough for a Manager to know and act according to generally accepted methods, principles, and norms. The situation forces you to change the rules of the game during the game itself. The Manager is forced to create the space of action itself, and in this sense, his actions are akin to the work of a Director. The theatrical and scenic approach to education is formed at the junction of the methodological practice of theatrical art and the space of anthropological problems. This method has been used in business education since 1992 not only at the State University of management, but also presented by us at universities in Moscow, the USA, Slovenia, and Poland. Indeed, each of us has several channels of perception of reality: visual, auditory, and kinesthetic (kinesthetic - bodily). This method allows for the harmonious development of all three channels of perception, which contributes to the adoption of nonstandard solutions.

Expert assessment of the method is given by the doctor of art, Deputy. Oleg Genisaretsky, Director of the Institute of Human rights of the Russian Academy of Sciences: the theater model has since ancient times been the basic cultural model for understanding and cultivating communication practices. Stagecraft, in contrast to other approaches to the development of managerial art, has mainly a physical and figurative expression and allows you to see yourself as if in a mirror, i.e. to have a "selfimage", and the other standing in front of you, and you and us together, located in the same space.

The implementation of the method provides an experience of action in a rapidly changing world due to the ability to organic action. Organic action involves a type of action where the thought, feeling and action of the Manager are combined in their instantaneity and unpredictability, confirming the creative nature of managerial work and in its close relationship with the organizational culture. It is necessary to highlight the increasing role of organizational culture in creative processes, its basic elements and ways to develop creativity, idea generation, flexibility, and motivation at the individual, group, and organizational levels.

\section{RESULTS}

The present research of the authors allows us to bring to a wide audience the main concepts and paradigms of management today and in the future. The authors did not stop at traditional and widely publicized methodological approaches, such as system, situational, complex, historical, etc. We have identified the retrospective approach, taking into account its relevance and often equating it with the historical approach. Given that management activities in socio-economic systems are creative, research has focused on the mainstream of uncertainty in management. At the same time, we used the results of more than twenty years of work of the theater workshop at the first national management Department of management theory, where the authors continue to work. Other researchers in the field of knowledge management and management have created textbooks, monographs on knowledge management, and published articles on specific issues, but in recent years research on this 
important methodological approach has declined [17, 18]. Therefore, in our research, we have highlighted the section on knowledge management as a concept of management science.

Given the lack of knowledge of the conceptual humanitarian approach based on the implementation of managerial anthropology, we also highlighted the results of our research in the "discussion" section.

According to the results of our research, we could not stop at such a phenomenon as entrepreneurial management. It is probably no accident that this century is also called the century of entrepreneurs, i.e. the century of entrepreneurs.

\section{CONCLUSION}

The authors of these studies hope that they bring to a wide range of readers the modern fundamental methodological conceptual approaches to management in socio-economic systems, namely modern, deliberately not considering the traditionally established methodological approaches. We are fully aware that when considering modern approaches, concepts and paradigms of management science, we also take into account the fact that the rejection of classical schools and established concepts of the past would not lead to a loss of manageability at all today, seeing only trends and approaches and remembering that everything new is forgotten old. After all, many of the discussed conceptual approaches to the effective implementation of management science achievements are often just myths about management.

We believe that the most promising research in terms of management methodology is to expand the conceptual approaches we have considered in terms of digitalization of the economy and management, and the development of artificial intelligence. Indeed, technologies in the field of data usage (artificial intelligence, foggy computing, supercomputer technologies, identification technologies, modeling, blockchain technologies, neural networks, etc.), communicating robots, additive technologies and additive manufacturing and the Internet of things formed the fourth industrial revolution. which will directly affect the practical implementation of the modern management concepts we have studied, without changing their essence. Emerging problems in the field of not only the realities of the digital economy, but also global problems related to the entry of humanity into a new digital ecosystem, cause the need to consider the main points of growth necessary for the further development of the dialogue between science, business and government, i.e. management.

The whole world is "covered or infected" by digitalization: $20 \%$ of the global economy's GDP is directly linked to it, and the automation of processes due to robotics is growing by $60 \%$ per year. And it is unacceptable to underestimate this factor, since it is a way to increase the efficiency and competitiveness of Russia as a whole.
Given the increasing role of intellectual resources, the authors are determined to continue research in the field of anthropologization of management, knowledge management, and the creative nature of managerial work in modern conditions.

\section{ACKNOWLEDGMENT}

The authors are grateful to the scientists of the State University of management for the results of research that we relied on. A huge thank you to everyone who made a contribution to the preparation of this article.

Special thanks to the Governor of Novgorod A. S. Nikitin, Dean of the Russian Academy of Sciences S. S. Serebrennikov, Professor of the Department of theory and organization of management of the State University of management A.V. Raichenko and the entire staff of this first national management Department.

The authors are ready to discuss the materials of the article and will be especially grateful for any feedback and comments, as well as suggestions and additions for further research.

\section{REFERENCES}

[1] T.J. Peters, R.H. Waterman, In Search of Effective Management, Progress, 1986.

[2] D.S. Sink, Performance management: planning, measurement and evaluation, control and improvement, Progress, 1989.

[3] P.F. Drucker, Tasks of management in the XXI century, Williams Publishing House, 2004.

[4] U. Ouchi, Methods of organizing production: Japanese and American approaches, Economics, 1984.

[5] Decree of the President of Russia dated May 7, 2018, No 204, Available at:

http://publication.pravo.gov.ru/Document/View/00012 01805070038 .

[6] G. Latfullin, A. Nikitin, S. Serebryanniko, Management Theory, Textbook for high schools, 2nd ed., The third generation standard, Peter, 2014.

[7] A. Raichenko, G. Avetisyan, O. Gromova, G. Latfullin, L. Orlova, F. Ibyatov, Interviewer and public organizations, in: Proceedings of the International Conference on Man-Power-Law-Governance: Interdisciplinary Approaches, 2019, pp. 425-430. DOI: https://doi.org/10.2991/mplg-ia-19.2019.79 
[8] S. Serebrennikov, G. Latfullin, I. Musayelin, A. Stulovsky, S. Kharitonov, Innovations as factor of sustainable development of economic systems, in: Proceedings of the International Conference on ManPower-Law-Governance: Interdisciplinary Approaches, 2019, pp. 185-190. DOI: https://doi.org/10.2991/mplgia-19.2019.79

[9] V. Smirnova, G. Latfullin, J. Baziyan, G. Sundukova, T. Shramchenko, S. Moldir, Transfer of knowledge and itsimpact on integration processes in the technopark, in: Proceedings of the International Conference on Man-Power-Law-Governance: Interdisciplinary Approaches, 2019, pp. 214-220. DOI: https://doi.org/10.2991/mplg-ia-19.2019.79

[10] G. Latfullin, A. Raichenko, Management Methodology, Textbook for high schools, Peter, 2019.

[11] G.L. Gantt, Labour Organization, Reflections of an American engineer on the economic consequences of the World War, VSNH, 1923.

[12] Innovative development: economics, intellectual resources, knowledge management: collective monograph, B.Z. Milner (Td.), INFRA-M, 2009, Available at: https://znanium.com/catalog/product/169902.

[13] I. Nonaka, H. Takeuchi, The Knowledge Creating Company: How Japanese Companies Create the Dynamics of Innovation, Olymp-Business, 2011.

[14] F. Bacon, Works in two volumes, "Thought" (Philosophical Heritage), 1978.

[15] D.J. Tees, The Economic Benefits of Knowledge as Assets: A New Economy, Know-how Markets and Intangible Assets, Russian Journal of Management 2(1) (2004) 95-120.

[16] M.V. Filatova, V.G. Smirnova, Creative activity management, How to organize a creative process in a company, LAP LAMBERT Academic Publishing, Saarbrucken, Germany, 2016.

[17] O.A. Koryakovtseva, I.I. Doronina, T.M. Panchenko, I.S. Karabulatova, Z.M. Abdullina, Research of category "Motivation" as a basic tool of personnel management, International Review of Management and Marketing 6(1S) (2016) 293-299.

[18] I.S. Karabulatova, M.S. Vykhrystyuk, N.G. Dolzhenko, E.I. Mychko, E.V. Potmenskaya, The Use of Stable Expressions in Modern Economic Discourse as an Emotional Increase in the Potential Impact on Purchasing Power, Space and culture, India 7(4) (2020) 283-292. DOI: https://doi.org/10.20896/saci.v7i4.488 